\title{
AN ENABLING TECHNOLOGY
}

\section{Von Hippel Award Winner Peter Hirsch Discusses \\ How Materials Science Functions to Create New Opportunities}

I am very honored indeed to have received the Von Hippel Award from the Materials Research Society, and to have joined the distinguished list of names of previous recipients of the award, in whose company I never expected to find myself.

I have accepted this honor as recognition not so much of what I might have contributed myself, but primarily of the contributions which my close colleagues and students have made over the years.

On an occasion like this it is perhaps appropriate to look back to get a view of what has been achieved in materials science, and in the fields in which I am interested in particular, over the last 35 years or so, to assess the changes in the nature of the science and its objectives, and to look forward to the future. In the $40 \mathrm{~s}, 50 \mathrm{~s}$, and 60 s we lived through a period in which the development of solid state physics led to a revolution in understanding of crystalline solids. In the field of mechanical properties of solids dislocation theory developed rapidly and in the same period electron microscopy and microanalytical techniques became available, which allowed materials to be characterized in unprecedented detail and on a fine scale, and which helped, inter alia, to establish dislocation theory on a firm basis. The general advances in electron theory of solids led to the revolution in semiconductor device technology, while the development of new polymers and plastics has led to impressive growth and diversity in application of these materials. The science of composite materials has been largely worked out and composites are likely to become of increasing importance in the future.

To the materials scientist interested in fundamental mechanisms it was a very exciting era. In many universities materials science became a new discipline, with the basic philosophy that the properties of metals, alloys, ceramics, polymers, etc., could all be understood in terms of the same fundamental principles, structural units and forces-electrons, atoms, crystals, defects, polycrystals, interatomic forces, thermodynamics, etc.-and that in this way macroscopic properties could be synthesized in terms of microscopic parameters.

Over the last ten years or so, there has been a growing realization that in the universities in the U.K. the interface between materials science and engineering has been neglected: the motivation for much of the advances in materials science and physical metallurgy had been to achieve a better understanding of basic mechanisms controlling microstructure-property relationships and work aimed at solving engineering problems, particularly relating to manufacturing technology, had not been emphasized sufficiently. In the case of microelectronics research this

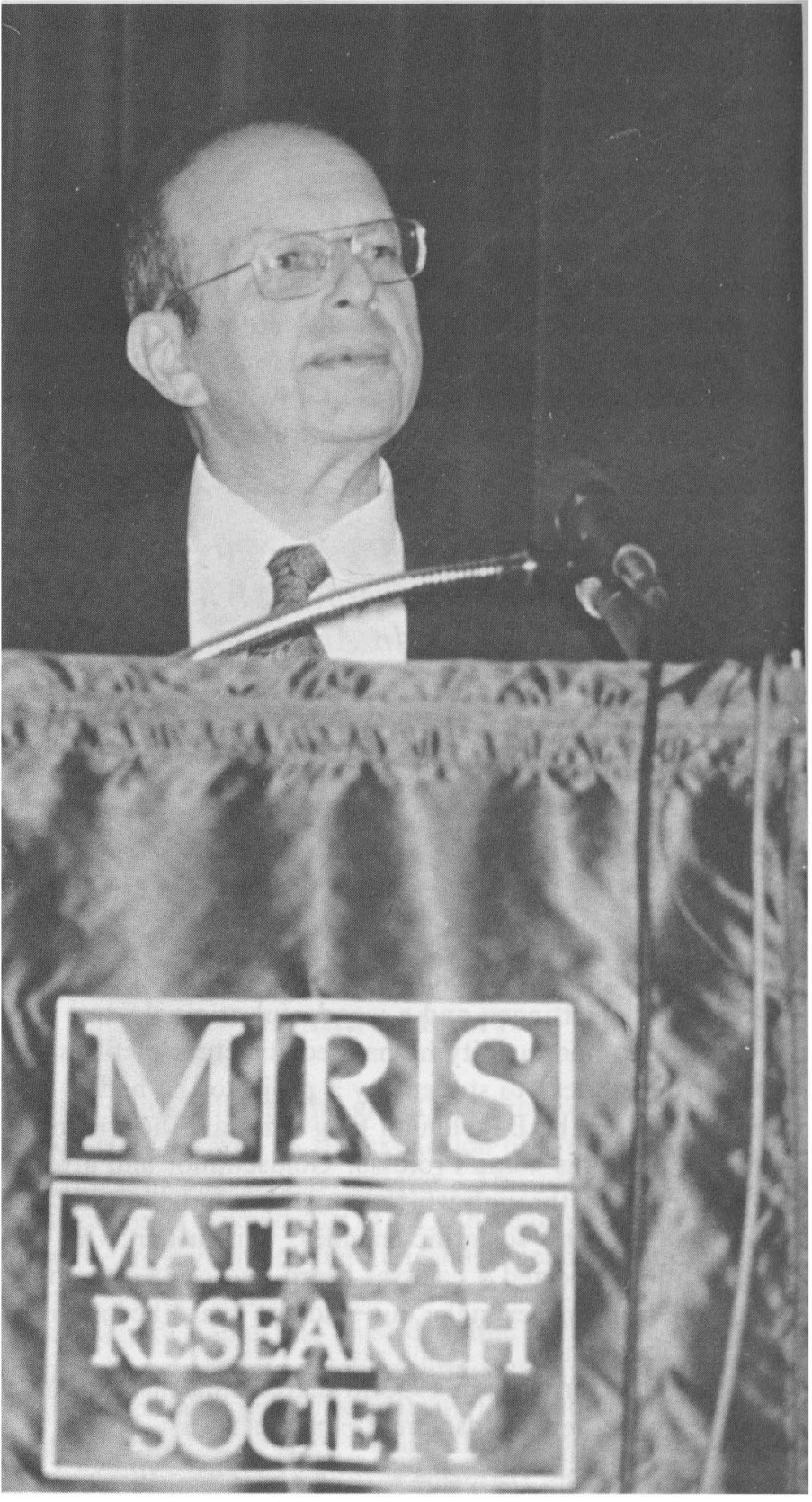

\section{PETER HIRSCH}

problem has not arisen; the development of new devices requires sophisticated processing and fabrication methods and monitoring by advanced, often electron optical techniques, areas in which the engineering interface is at the frontier of knowledge. Consequently in this area the universities and industry collaborate closely together, and 
the materials "science" fulfills its proper function of an enabling technology.

With regard to university materials science contributions to other areas of engineering, in the years to come we are likely to see a gradual change in the balance of the work carried out in materials science departments in the U.K., with a greater emphasis on materials technology to enable engineering problems and opportunities, particularly relating to manufacturing routes, albeit long term problems, to be addressed. This will need greater interaction between university departments and industry, and between the materials scientist and engineer: within industry both must become involved in the design function, aimed at manufacturing components with particular specifications economically. Perhaps this problem does not exist to quite the same extent in the U.S., but in the U.K. there is a need to develop materials engineering more generally in university departments, and more emphasis needs to be given to how a particular engineering objective can be achieved. And we should perhaps review our teaching philosophy to ensure that we give enough attention to engineering rather than

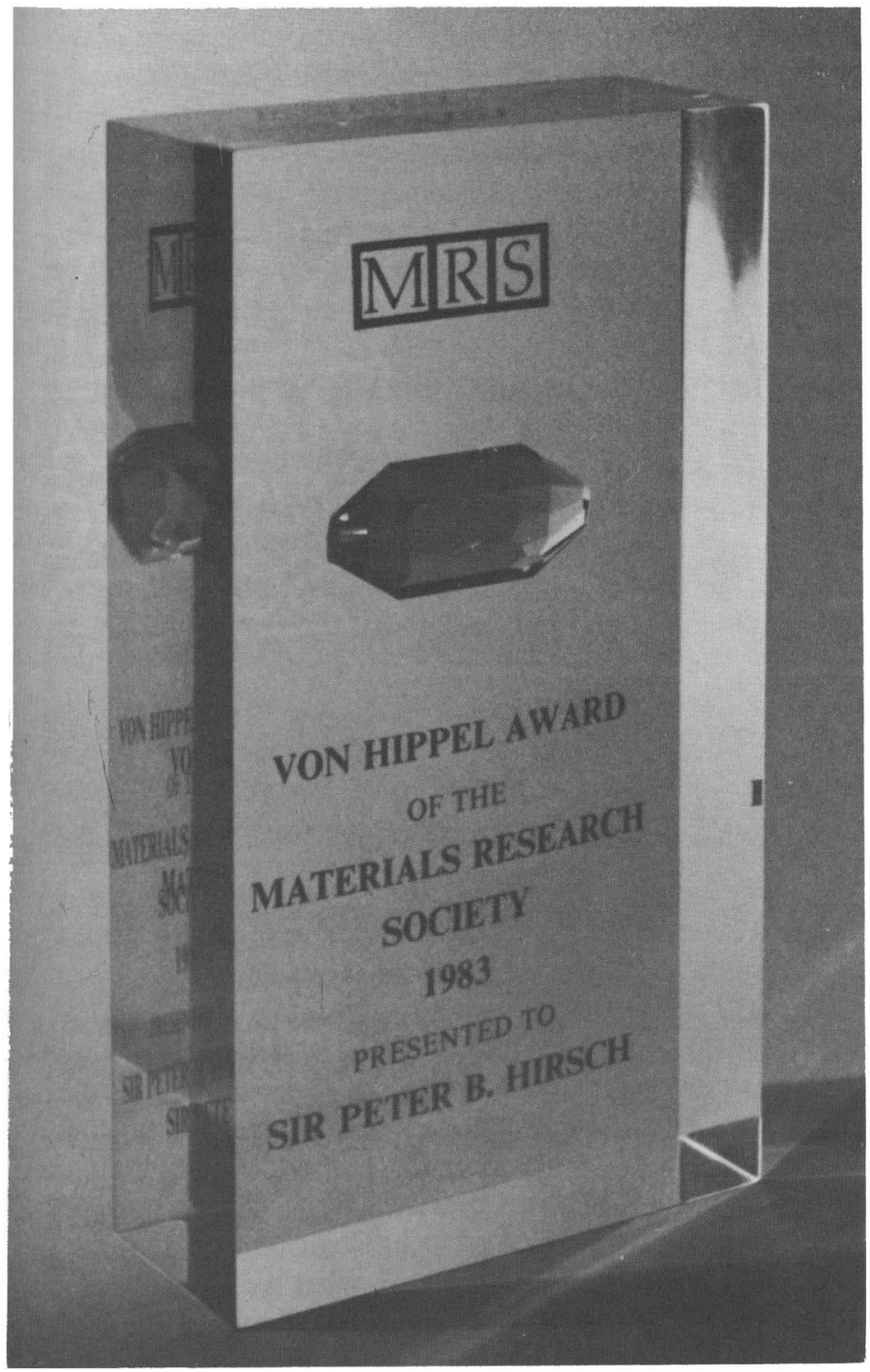

THE VON HIPPEL AWARD only to microscopic aspects, to end uses of materials and the routes by which they are reached, to methods of fabrication, joining, processing, materials selection and design.

Inevitably in a period of financial constraint such a change of emphasis means that it will be more difficult to find support for research projects aimed at furthering our basic understanding of some property if this is not clearly related to achieving some engineering objective, or for developing some new material if there is no recognized need for it. While a shift in emphasis is undoubtedly necessary, it must not go too far; the danger is that original and potentially innovative but speculative work may be stopped. Such an extreme trend must be resisted strongly; if we only respond to recognized needs, we will tend to develop only the technologies which we can already perceive today. But the origin of real technological change can usually be traced back to some basic or speculative work, coupled often with someone's appreciation of potential application of the unexpected result. I saw recently in a paper by Derek Birchall a quotation of Edison's own description of his invention of the phonograph:

"I was," he said, "singing into the mouthpiece of a telephone when the vibration of the voice sent the fine steel point into my finger. That set me thinking. If I could record the actions of the point and send the point over the same surface I saw no reason why the thing should not talk."

Such are the ways in which the technologies of tomorrow, those we have not yet thought of, can originate, and how new opportunities are created!

I mentioned at the beginning that I would attempt to look into the future. It follows from what I have just said that we can only make predictions about the technologies we know already today. There are obvious growth areas in materials science and technology associated with semiconductor devices and the drive for miniaturization; the scale seems to be halving every two years at the present time. I believe also that there will be an increasing demand for composites, for glassy alloys probably initially for electro-magnetic applications, and that there will be a promising future in the long term for high temperature ceramics in engine applications.

My recent experience with the U.K. Atomic Energy Authority in the nuclear field leaves me in no doubt about the importance of developing and validating materials and fabrication processes which will enable components to be made whose integrity can be assured for 40 years in service. Failure of critical components can be extremely costly in terms of lost revenue. The emphasis here must be on long term reliability, and there are similar changes in the field of biomedical materials. Finally, I believe that in due course the new stronger and tougher hydraulic cements will find applications in the marketplace. The future potential of these materials is considerable-the cost of the raw materials is low, the energy consumed in manufacture is relatively

\section{[Continued on Page 31]}




\section{HIRSCH}

\section{[Continued from Page 5]}

small, components can be easily fabricated, and hardening takes place at ordinary temperatures. The annual production of ordinary cement is 1,000 million tonnes per year, and with steel it is the most important material in the construction industry; yet our understanding of cement properties is nothing like as advanced as that of steels. Although there has been an increasing interest amongst materials scientists in cement research in recent years, I believe that we are only at the beginning of an exciting growth area; some of the properties of the new low porosity cements, e.g., Young's modulus of $50 \mathrm{GPa}$, flexural strength of $150 \mathrm{MPa}$, and fracture toughness of $1 \mathrm{~kJ} / \mathrm{m}^{2}$ are comparable with those for plastics, some ceramics and some metals, and although, no doubt, validation under service condition will take time, such materials are likely to replace certain plastics, ceramics, and metals for some low temperature applications in the future.

I want to return now to the point I made earlier that materials science and technology, and I find it difficult to draw a clear distinction between the two, is really an enabling technology, aimed at providing the engineer with the materials and processes to turn a design into hardware, and providing the engineer with new opportunities. To bring this about, it is absolutely essential for the engineer and materials scientist to work closely together and to be aware of each other's needs and opportunities. This theme was emphasized in the talks we heard yesterday in the session on "The Role of Government, Industries, and Universities in the Support and Performance of Materials Research." It is also a central theme in the conference program of this and previous MRS conferences. It is this aspect of bringing scientists and engineers together in symposia concerned with current technological problems and developments, which makes these conferences so stimulating and important. The Boston conference has now established itself as an important annual event in materials science and technology. I am very honored and grateful not only for the award but also for inviting my wife and me to this conference, and I am only sorry I cannot stay for the whole week. On a personal note, I am very pleased to have the opportunity of meeting so many of my old friends and colleagues again, and it is a matter of considerable satisfaction that amongst your contributors and symposia organizers are several members and ex-members of my Oxford department, and members of the AEA. I want to thank you once again, Mr. President, and members of the MRS, for honoring me in this way, and my wife, for giving me the support which enabled me to do the work which has led to this honor.

\section{SYMPOSIUM M}

\section{[Continued from Page 25]}

Professor R. A. Brown's (MIT) paper was concerned with an analysis of meniscus-defined crystal growth. The shape of the crystals and stability of the processes for EFG, floating zone, and LEC growth are dictated by the interaction between heat transfer from the melt, crystal, and surrounding with the shape of the molten zone, which is dictated by surface tension. In each system the temperature fields in the melt, crystal and die (for EFG) and the shapes of the melt/solid and melt/gas interfaces are calculated by a new finite-element algorithm for solving simultaneously two-dimensional heat transfer models in each phase and the Young-Laplace equation for meniscus shape. Calculations gave predictive results and the applications of the models are only limited by our knowledge of the high temperature thermophysical properties of the material in question.

Dr. E. R. Weber (Berkeley) reviewed the diffusion behavior of several 3-d elements $(\mathrm{Co}, \mathrm{Ni}, \mathrm{Cu})$ in $\mathrm{Si}$ and contrasted their behavior with that of $\mathrm{Au}$. $\mathrm{Cu}$ and $\mathrm{Ni}$ enter
Si interstitially and diffuse rapidly. The well known diffusion data for Au suggest that during the initial diffusion stages, it diffuses via an interstitial mechanism and then changes over to a substitutional mechanism, thus accounting for the observed decrease in diffusivity at long times. Neutron activation, EPR and DLTS measurements were used to confirm the two well known deep donor and acceptor levels and he showed that $\mathrm{Fe}$, as an accidental impurity, leads to Au-Fe pairs. Two new deep levels are formed which can be ascribed to these pairs. Suitable heat treatments for Si:Au devices were obtained that eliminate the device instabilities that arise from the presence of $\mathrm{Au}-\mathrm{Fe}$ pairs.

\author{
J.H. Wernick \\ Bell Laboratories \\ F.F.Y. Wang \\ State University of New York, Stony Brook \\ Chairmen
}

